\title{
Removing the blinkers: what a process view learns about G2G information systems in Flan- ders (part 2)
}

\author{
Lies Van Cauter ${ }^{1}$, Monique Snoeck ${ }^{2}$, Joep Crompvoets ${ }^{1}$ \\ ${ }^{1}$ KU Leuven, Public Governance Insitute, Leuven, Belgium \\ (Lies.VanCauter, Joep.Crompvoets)@ soc.kuleuven.be \\ ${ }^{2} \mathrm{KU}$ Leuven, Research Centre for Management Informatics, Leuven, Belgium \\ Monique.Snoeck@kuleuven.be
}

\begin{abstract}
Information sharing across the public sector is a precondition for innovation. The reality today is that data are scattered throughout administrative services. Creating government-to-government (G2G) information systems (IS) has the potential to sustain fluent data flows. Despite this potential, G2G IS projects fail to deliver the expected benefits. Factor research partially explains why so many G2G information systems fail. In this paper we take a broader perspective by applying process research to study six recurrent problems of Flemish G2G IS in their dynamic context. We test whether Sauer's needs and supportpower analysis can provide additional management insights concerning G2G IS projects. Our results, based on interviews and focus groups, show that seemingly controllable problems have much deeper roots that require managers' action.
\end{abstract}

Keywords. IS failure + G2G * process management

\section{Introduction}

In November 2014 the Organisation for Economic Co-operation and Development (OECD) called for action to enable public sector innovation. A core precondition is free flowing data, since shared information provides a basis for simplification, accountability or collaboration and allows organisations to learn collectively [17].

The potential added-value of free flowing data is high, but unfortunately, the reality today is that data are scattered throughout administrative services. The Weberian bureaucracy, characterized by its strict task allocation and hierarchy, has led to fragmentation of policy and service delivery. This problem is pervasive: the need for information sharing exists both across different levels of governments (vertical dimension) as among different governmental agencies (horizontal dimension) [28].

ICT is perceived as an important driver of change because the creation of digital government-to-government (G2G) information systems (IS) has the potential to sustain free data flows [2],. Unfortunately G2G IS projects continue to fail to deliver 
expected benefits [4],[24]. This problem has heavily been researched during the last decades, without resulting in a great improvement of failure rates. One cause might be that for a long time a rational and technical view on failure dominated [19]. Positivistic researchers and project managers believed that problems can be eliminated if failure factors are listed and if management can detect and eradicate these linear failure factors. Yet eliminating failure factors does not warrant success. Rational factor research ignores the context of an IS as well as the dynamic non-linear interactions of (non-)technical factors such as legislation, politics, economic or cultural factors [24]. Rational project managers tend to follow fixed goals and try to minimise the risk of random context events, as such they only see a part of the IS failure puzzle [12].

In 2014 Dwivedi et al [8] called for research that includes a larger part of the failure puzzle by incorporating local contingencies and the dynamic environment of ISs. A growing research stream that connects to this call is the 'process perspective' (e.g. Lee \& Liebenau, Markus \& Robey, Sauer[8]). Process managers look at the interaction between an IS, its stakeholders and context factors. An IS project does not exist in a vacuum [12],[25], compatibility with a given environment is a key precondition for innovation [5]. Stakeholders of G2G ISs interact dynamically and may have diverse interests which can e.g. result in sabotage of project goals. A major cause of failure is the inability to deal with these [2]. The ability to adapt to environmental developments and changing stakeholders' needs, determines governmental innovation [2], [12]. Sauer believes that managers who are confronted with troubled ISs, could start with an analysis of their situation by conducting a needs assessment: What problems need to be solved and what stakeholder support would meet these. This should be followed by a support power analysis: Who has the power to provide the required support? By conducting such analysis, managers will be more aware about context and dynamic stakeholder interactions that influence their ISs (i.e. a process perspective) [22]. We elaborate further on Sauer's work, as the main research question is:

Can the needs and support-power analysis of Sauer provide additional insights for G2G IS management in Flanders?

In a previous article [23] we conducted a needs and support-power analysis, but limited ourselves to the study of recurrent technological and political problems of G2G IS projects in Flanders. The analysis showed that factor research can appoint recurrent problems but that Sauer's process perspective provides extra insights concerning the context of these problems and support (difficulties) of relevant stakeholders. This article investigates whether conducting the same analysis for recurrent economic and juridical problems of G2G IS projects in Flanders, can add insights to the prior analysis results. The specific research question of the paper is: Does the analysis of the economic and juridical recurrent problems, via the needs and support-power analysis of Sauer, provide additional insights for G2G IS management in Flanders?

The structure of this paper is as follows. The theoretical framework is sketched in part two. Methodology is described in part 3. The actual analysis is presented in part 4 , it is followed by a discussion of the results in part 5 . We conclude in part 6 . 


\section{Theoretical framework}

Sauer sees ISs as the product of a process which is open to flaws. This process consists of an initiation, development, implementation and operational phase, it may be problematic. An innovation process can be split up in a need and a support management process which may be influenced by contextual uncertainties. In order to continue the innovation process, a project organisation requires enough support: support is searched during the support management process. If there is too little support, the endurance of the innovation process and the whole IS is threatened [22].

Sauer modelled a triangle of dependences: ISs exist to serve stakeholder's interests. They require a variety of support if they are to function at all. The IS's project organisation has a special role in innovating the system. Support for carrying out this role will only be given if supporters' interests are served. Managers could use a needs analysis to define the problems with which the project organisation will be confronted during the innovation process. This analysis further pictures the context influences and available problem solving mechanisms. A support-power analysis helps additionally to determine who has the potential power to provide the required support.

\subsection{Needs analysis}

The project organisation's needs analysis will consist of two parts: a) an analysis of problems and b) an analysis of the required support to solve these problems:

a) Analysis of problems is twofold: (1) map the problems to be solved, (2) do a context scanning. Context helps to define problems but constraints originating in this context may make the innovation process problematic. The context is analysed along six dimensions: 1. human factors, 2. history, 3. technological process, 4. structure, 5 . politics and 6. environment. Environment is subdivided in: 6.1.customers, 6.2. suppliers, 6.3.competitors, 6.4.technology, 6.5.regulators, 6.6.interests and 6.7.culture [22].

b) The analysis of support looks at available problem-solving mechanisms G2G ISs are often ineffective in transferring data between organisations. These systems are confronted with complex combinations of problems. Managers should understand problems in depth, in order to deal with these in an effective manner. In the project organisation the idea champion takes up this vital task. The potential of an innovation is also dependent on the context in which information sharing takes place [22].

\subsection{Support power analysis}

The support power analysis investigates who is able to provide support identified in the needs analysis and what other relations may affect stakeholders [22]. It can be applied at any stage of a G2G IS project. Sauer advices to conduct this analysis often. An idea champion should acknowledge his dependence on others. Information sharing requires both thinking about the own organisation and of external actors [17]. The latter may support/obstruct a project while trying to protect their core values and may react in an unpredictable way to interventions. Costs- benefits are not evenly divided, some stakeholders win, some lose. Idea champions should be sensitive for chances of 
random decision making, managing these becomes in itself dynamic, management strategies are dependent on the situation at hand and stakeholders' reactions [7], [12].

\section{Methodology}

\subsection{Data collection}

In 2012 an exploratory research on trends and challenges of G2G IS projects was conducted. 20 experts of all Belgian governmental levels (i.e. local, provincial, regional and federal) were interviewed on this matter. In 201432 idea champions of G2G ISs in Flanders (Belgium) were brought together in five focus groups to discuss IS challenges, trends and the management thereof. We detect an overlap between the findings of both studies: managers in G2G IS projects face recurrent problems, which we structured via Sauer's 'needs and support-power analysis framework'. Technical/political problems were discussed in a previous paper [23]. This paper analyses recurrent economic/juridical problems and focuses primarily on vertical ISs between the Flemish regional government and local governments. However, since for some IS projects several Flemish organisations were involved, this adds a horizontal dimension. The next paragraphs describe data collection techniques in more detail.

Interviews 2012. Interviewing is a common data collection technique in IS research. In 2012, 20 experts on G2G IS projects were interviewed face-to-face on trends and challenges of G2G IS projects. Interviews were carried out over a three-month period. The interviewees represented local or provincial stakeholder groups, managed a successful G2G IS project or tried to monitor several G2G ISs. They worked for 14 different organisations at all governmental levels, this was a deliberate choice: by collecting different points of view, the risk of attribution bias was reduced. The interviewer asked open-ended questions to probe interviewees when interesting topics surfaced [20]. Both (non-)verbal language was captured. Each interview lasted between one and two hours and was transcribed with permission. The policy documents and legislation interviewees referred to, were studied as well. All interviewees received an end report. After 20 interviews, a point of saturation was reached.

Focus groups 2014. A focus group (FG) is a group of individuals assembled by researchers to discuss and comment on a certain topic. It allows to obtain a variety of perspectives from a single data-gathering session [20]. Mainly the last decade FGs are gaining visibility and acceptance in IS research [3]. In 2012 we created an inventory of existing G2G ISs in Flanders. Based on this inventory, 40 IS idea champions were invited to participate in FG discussions. Five refused cooperation, five others did not show up. We slightly over-recruited the number of idea champions and reached as such the optimal number of 6 or 7 participants per session. A pretested questioning route was used to guide the conversations. The moderator briefed the participants, tried to create an informal sphere and ensured that everyone could have a say. She encouraged dialoguing via follow-up questions and by showing a stimulating body 
language. A senior researcher took up the role of assistant moderator. She observed body language, took notes and summarised the viewpoints. After 5 sessions saturation was achieved [3]. For a more detailed description of the data collection see [23].

\subsection{Data analysis method}

The interview and FG questions are not based on a specific theoretical model so that the data could speak for itself (an inductive approach). The five stages model of Krueger [14] was used to interpret the data. (1) Familiarisation: The researcher gets familiar with the major themes by reading the transcripts. (2) Themes: She develops categories within the major themes based on a questioning route. (3) Indexing: Data within and between cases are compared. (4) Charting: Data are reduced, important quotes rearranged under new codes. (5) Mapping and interpretation: Links between quotes are interpreted to make sense of the data as a whole. By studying the data, a series of G2G IS problems surfaced. We grouped these in 4 main categories: A) technological, B) political, C) economic and D) juridical recurrent problems. A) Recurrent technological problems have to do with the business case, IT infrastructure, developers, planning and security. B) Political recurrent problems involve top management support, user involvement and the skills/position of the idea champion. C) Economic problems are about the need for (in)tangible resources. D) Finally too much/less change in legislation, involuntary use and privacy form recurrent juridical problems. 287 pages of transcripts were coded in the qualitative data analysis programme NVivo. Data were analysed in two stages. (1) The problems detected from the interview data of 2012 were compared to the FG results of 2014. (2) Recurrent problems were compared to Sauer's framework by applying a needs and support analysis.

\section{$4 \quad$ Analysis}

The data analysis of interviews and FGs reveals an overlap in problems concerning political, technological, economic and juridical issues. Considering that these problems reoccur in both studies, we assume that they are rather structural and widespread for Flemish G2G IS projects. Factor research lists these problems too but ignores their interaction and context. It misses as such a part of the IS failure puzzle. In contrast, we take a process view by conducting a needs and support-power analysis on the recurrent problems. This enables us to research whether additional insights can be found via the process perspective. We found that the need and support analysis of political and technological recurrent problems indeed provides additional insights [23]. In the next paragraphs we will analyse recurrent economic and juridical issues and research whether these too provide additional insights. Due to space limits only the six most prominent economic and juridical recurrent problems are presented. Per problem three main things are described: (1) the problem to be solved (= problem description), (2) which context elements influence the problem (= context), and (3) which mechanisms can solve these problems and whose support is relevant therefor (= support). Every problem is influenced by several context elements. These elements 
are numbered and the applicable context category is mentioned between brackets. These numbers are referred to in the description of the support in order to motivate which support element relates to which element of the context

\subsection{Economic agreements}

To set up and run a G2G IS project, stakeholders must agree to provide tangible resources such as money/personnel and intangible resources (i.e. data, information) [4].

\section{Problem 1: Money.}

Problem description. A sufficient amount of money should be spent on a G2G IS for development, maintenance and adaptions: Who will finance what and when?

Context. Several context factors influence this need. (1) A macro factor is the economic crisis, due to budget cuts the willingness to do something for another government dropped (environment) and (2) funding to stimulate information sharing is under pressure (environment). (3) The budgetary capacity of governments differs widely but is relevant for obtaining adequate hardware, software and IT knowledge (structure). (4) Funds might stimulate municipalities with a small capacity, but in the past, Flemish funds were sometimes unilaterally abandoned, creating local distrust (history). (5) The configuration of Flemish departments stimulates silo creation: every department has its own budget. Information sharing challenges the classic revenue model (structure). (6) Flemish politicians see it as a means for cost reduction but " $a$ G2G IS is a current account. If there is a change in the IS, stakeholders have to invest money to adapt to these changes." A lack of invested resources leads to suboptimal solutions. Ministerial priorities can influence the annual budget of an IS too (politics).

Support. (1-2) Funds to stimulate use are not desirable in times of budget cuts but may convince stakeholders to support an IS that has to outgrow technical problems. G2G ISs require immediate investment costs, benefits are only obtained over time. Funds are useful to bridge the period when other benefits cannot yet be reaped. (3) Cities have more means and a stronger bargaining power than small sized municipalities. (4) Support is given more easily when increased performance is expected. (5-6) If a ministerial cabinet supports an IS, it is easier to ask for more resources/ cooperation of other departments. Respondents advise to prevent regular IS changes and to explain why these changes are needed.

\section{Problem 2: Personnel}

Problem description. Every participating organisation in a G2G IS project should invest a sufficient amount of personnel time at all stages of the project, in order to tackle interoperability or IT problems and in order to enable data input and analysis.

Context. (1) In a G2G IS project the number of data inputters differs widely per organisation. $75 \%$ of the Flemish municipalities has less than 20.000 citizens and takes up many tasks with few people. Cooperation in G2G ISs is cost demanding for small municipalities, resulting in higher investments than gains(structure). "They chose their own priorities: not all data requests from the Flemish government will be answered." (2) Governments often lack IT skilled personnel (structure). (3) E-government is de- 
manding as it often requires a duplication of services (e.g. due to the digital divide or during the transition to an IS) (human factors \& technological process). (4) Every governmental organisation works and evolves on its own speed (history).

Support. (1) Due to their size, cities have more negotiation power than smaller municipalities. Their ISs may be more advanced than the Flemish ones. Cities claim that if the Flemish government wants their support, it should recognise their expertise instead of imposing ISs. The respondents think that users with a small capacity can be motivated to support an IS by the availability of a help desk. (2-4) Difference in capacity/speed might be tackled by the creation of several entrance levels.

\section{Problem 3: Intangible resources}

Problem description. G2G ISs need to be fed with data from different parties.

Context. (1) Stakeholders in G2G context often face a lack of shared goals (environment). (2) The Flemish government aims to collect policy info for the whole of Flanders. The required data are available at local level but municipalities do not intend to spend their limited resources on making their data available to the Flemish government when their benefit is uncertain (environment). (3) This problem is exacerbated by previous experiences that it is hard to obtain data in return from the Flemish level (environment). (4) The Flemish government recently agreed to standardize on 'open data', but not all departments welcome this strategy. Some ISs are financed by 'pay per data use', but who will pay for 'open' ISs is not yet clear (environment).

Support. (2-3) The respondents notice that if the Flemish government wants local governments to support an IS, it should see them as data sharing partners and not as data subordinates. (4) Respondents think that stakeholder support for opening ISs is only realistic if politicians provide an alternative finance model for 'pay per use'.

\subsection{Legal agreements}

Rules and legislation are mostly created to ensure quality, equity or responsible resource use. But these can restrict innovation if they cannot be easily adapted to specific needs or a dynamic environment [17]. In our research we found 3 recurrent legal problems that concern change in legislation, voluntariness of use and privacy issues.

\section{Problem 4: Change in legislation and regulations}

Problem description. Legal or jurisdictional aspects may hinder the progress of egovernment. Legislation and regulations need to be altered or sometimes developed.

Context. (1) The legal status of a digital G2G IS might not be recognised, even if it is, compared to its paper counterpart, the authentic source (structure). (2) Digitisation often comes after legislation. IS stakeholders may find their activities prohibited by formal rules. The option to simplify legislation is regularly ignored as idea champions lack time or the juridical capacity to perform such an exercise. As a consequence digitisation does not simplify the multiple adapted/expanded rules but builds yet another level of legislation (structure \& environment). (3) Politicians change legislation/regulations regularly, which brings along an adaption cost for ISs (environment). 
Support. (1-2) The respondents are less likely to support complex ISs. As such they believe that reengineering legislation is necessary. "IT'ers tend to see legislation as hard to programme, holy and untouchable. They should realise it can be adapted."

\section{Problem 5: Voluntariness of use}

Problem description. An IS needs to be used to be successful. Voluntariness of use differs per case, rights and obligations may be laid down in rules and regulations.

Context. (1) The Flemish government often legally obliges IS use for local governments. Non-use is not always reprimanded (regulators). The "bell tower principle" states that if the Flemish government asks for municipal efforts, it should provide a financial reward, this is often ignored in practice (history). (2) Another option is using the carrot by funding data exchange, yet this created perverse effects in the past (e.g. minimal data import to get the money) (environment). (3) A third option is voluntary participation in an IS based on a win-win (environment). (4) The need of local data for the Flemish government often originates from European requests (regulators).

Support. (1) Due to a lack of resources many local governments will not provide support to low priority G2G ISs. Use of legislation alone is an indolent solution for getting support, it may result in ISs plagued with poor data quality. As local governments become more emancipated, they tend to refuse support even if it is legally obliged. (2) Support can drop severely when funding stops. (3) Municipalities are tired of double data requests, they want to support data reuse. The respondents also advice to ask potential users who refuse to cooperate why this is the case.

\begin{tabular}{|c|c|}
\hline \multicolumn{2}{|l|}{ CONTEXT } \\
\hline HUMAN FACTORS & TECHNICAL PROCESS \\
\hline $\begin{array}{l}\text { - Digital divide: duplication of services induces dupli- } \\
\text { cation of data input efforts }\end{array}$ & $\begin{array}{l}\text { - Duplication of services induces duplica- } \\
\text { tion of development efforts }\end{array}$ \\
\hline HISTORY & POLITICS \\
\hline $\begin{array}{l}\text { - Unilaterally adapted funds, low local trust } \\
\text { - Organisations work at their own speed } \\
\text { - Ignorance 'bell tower principle' }\end{array}$ & $\begin{array}{l}\text { - Politicians underestimate (recurrent) costs } \\
\text { - Ministerial priorities influence finances } \\
\text { - Changes legislation } \Leftrightarrow \text { adaption cost ISs }\end{array}$ \\
\hline ENVIRONMENT & STRUCTURE \\
\hline $\begin{array}{l}\text { - Eco. crisis, dropped willingness to do sth. for others } \\
\text { - Culture: hard to locally obtain Flemish data } \\
\text { - Interests: distrust, lack of shared goals, desire for } \\
\text { benefits in return for data } \Leftrightarrow \text { obliged use } \\
\text { - Interests: win/ funds as stimulus } \Leftrightarrow \text { perverse effects } \\
\text { - Interests: Vagueness privacy as an excuse for not } \\
\text { sharing data, open data } \Leftrightarrow \text { pay for use } \\
\text { - Regulators: no reengineering, data sharing may be } \\
\text { prohibited or obliged. Problem legal status digital ISs } \\
\text { - Regulators: European data reauests }\end{array}$ & $\begin{array}{l}\text { - Differing budgetary \& IT capacity } \\
\text { - Budgetary configuration stimulates silos } \\
\text { - Low (IT) personnel capacity } 75 \% \text { munici- } \\
\text { palities, own local priorities } \\
\text { - Time intensive to change legislation, lack } \\
\text { of juridical personnel capacity } \\
\text { - Time consuming to get permission of } \\
\text { (conflicting) privacy commissions }\end{array}$ \\
\hline
\end{tabular}

Fig. 1 Overview of legal and economic context constraints of Flemish G2G IS projects

\section{Problem 6: Privacy}

Problem description. Governments that share information have to respect the fundamental right of privacy.

Context. (1) In order to share information, G2G IS projects often need a permission of a privacy commission, but obtaining permissions is time consuming. The more 
because the Belgian federal structure may make several privacy commissions competent according to the applicable policy level or policy domain. Respondents complain that the advice of different commissions may conflict (structure). (2) Data may not be shared or reused due to data protection regulations. It is still rather unclear if reused data may be enriched. The respondents see privacy as a vague issue (environment).

Support. (1-2) An IS often needs the support of a kind of privacy commission(s), which can be time consuming. The respondents ask for more clarity on privacy issues. They propose to only let the most relevant commission decide, when several privacy commissions are authorised. The respondents believe that on the other hand, privacy protection may also be a misused argument to refuse support to provide data.

\section{Discussion}

3 economic and 3 legal recurrent problems for Flemish G2G IS projects were uncovered by the analysis. Economic agreements have to be made to prevent problems with (in)tangible resources such as (1) money, (2) personnel, (3) data/ information. Agreements on legal/juridical issues are crucial to prevent problems with: (4) too much/few changes in legislation/regulation, (5) voluntariness of use and (6) privacy. Several researchers confirm the importance of these problems: In terms of the economic perspective, previous research shows that it is hard to decide who will bear the costs of G2G IS projects [13], and that a lack of capacity is indeed a major barrier [9],[16],[18]. Financial support may promote ISs but obtaining funds can be tough [13]. Intangible resources are valuable, stakeholders want a benefit in return[1]. Concerning the juridical perspective, other scholars also found that G2G ISs may mismatch formal rules [11],[15] and require a time-intensive creation/adaption of legislation/regulations [11],[19]. They confirm that rules may be used as an excuse to block projects [17]. While ISs based on voluntary collaboration have more chance to succeed. Finally, the lack of clarity in privacy policies is a barrier for G2G ISs [9],[25].

This article investigated recurrent economic and juridical problems of G2G ISs in Flanders. It is an addition to a previous article about recurrent technological and political problems. Taking a look at the whole picture is interesting. All four categories of problems are based on the study of interviews in 2012 and focus groups in 2014. In total we found 14 recurrent problems. Each problem on itself is not new, factor research has listed these as well [21]. Yet, we go further by describing influencing context and support issues of these problems. By conducting a needs and support-power analysis it became clear that seemingly controllable problems have much deeper roots. Even more, context and support elements of different problems are interrelated.

In the previous paper elements pointed to: (1) a tendency of Flemish idea champions to merely focus on Flemish interests, (2) a lack of coordination of IS initiatives and (3) a political disinterest in ISs. These discourage local stakeholders to support Flemish G2G ISs. This paper studied if a needs and support-power analysis of economic and juridical recurrent problems can provide additional insights: First, the previous findings are confirmed, the 4 categories of problems seem to have similar roots: 
(1)The ignorance of the bell tower principle, a unilateral adaption of funds and a difficulty to locally obtain Flemish data, point to the tendency to merely focus on Flemish interests. (2) A budgetary configuration that stimulates siloisation and a lack of (G2G) shared goals \& benefits, point to a lack of integration. (3) The unrealistic expectation of quick savings without much expenditures points to a political disinterest and lack of knowledge of ISs. Second, the analysis of economic and juridical factors adds two root elements. Local stakeholders seem also discouraged to support Flemish G2G IS projects because of (4) major differences in organisational capacity (e.g. differences in budget, IT, personnel capacity or e-government speed) and (5) juridical complications such as complex piled legislation, the need for duplication and the insecure legal status of ISs. Flemish idea champions may become discouraged by conflicting privacy commissions and by the prohibition of data sharing. Knowing why local stakeholder support may be discouraged is a start, but it is essential to know which action Flemish idea champions can take to tackle recurrent problems at their roots:

Action 1: Move from hierarchical project management to network process management. The main focus on the own Flemish interests and a lack of coordination between different departments point to a 'hierarchical-project' way of managing. Project managers focus on clear goals and a predefined output while minimizing the risk of random events and ignoring the process [7]. This approach is not compatible with the environment of G2G IS project in Flanders. A 'network-process' management approach would allow to actively involve local stakeholders, as such Flemish idea champions could get an image of their core values. They may also get more conscious of the world around them and might better coordinate actions which allows better conflict anticipation. Local and Flemish stakeholders continually interact and adapt to their environment. These dynamics make G2G IS projects difficult to manage. Managers must also realise that the involvement of many people risks scope creep [12].

Action 2: Go for the win-win: manage needs, capacities and speeds. Often legislation mandates without providing resources, which negatively influences mutual trust [11]. We notice a trend of municipalities to refuse cooperation even if it is legally obliged. They argue they are busy with their own business and have other needs [13]. Flemish idea champions are dependent from other parties. Our research results show that local and Flemish stakeholders expect some benefits in exchange of their data (e.g. funds, increased performance, less duplication or data reuse). If funds or a legal obligation are the only drivers to provide data, perverse effects (e.g. poor data quality) might surface. A win-win between partners is definitively more stimulating [15]. Bigdeli et al [4] state that the resources of local governments are more limited than those of central/regional governments. Yet even within one group of stakeholders, in this case municipalities, there is a large capacity difference: the smallest Flemish municipality counts 80 inhabitants, the largest 480.000. Populous local governments, with many resources, are more likely to adopt e-government than smaller less resourceful municipalities [25]. In general, it is hard for Flemish idea champions to deal with the variety of needs, capacities and speeds [10]. This might be overcome by involving small, medium and large local governments and providing several IS entrance levels. 
Action 3: Make politicians more aware of their juridical deeds and the interaction with ISs, dare to redesign legislation. Bekkers believes that the design of an IS should come before the creation of new legislation [1]. Flemish politicians are continually generating new legislation, which influences organisational flexibility [4]. If there is a change in legislation, business processes and their supportive systems have to be adapted [19]. G2G IS projects are burdened by a web of detailed and even conflicting rules/regulations [1]. The short term orientation of Flemish politicians and the bureaucratic nature of public organisations (e.g. focus on predictability, legal security \& equality) frustrates innovation [10]. Flemish idea champions should try to make politicians aware of their ignorance of ISs and the related juridical complications.

\section{Conclusion and future research}

This paper studied the roots of six recurrent economic and juridical problems of Flemish G2G IS. We aimed to extend the body of knowledge by investigating how local contingencies and support-power relations affect the likelihood of failure of Flemish G2G IS projects. The research findings show that a needs and support power analysis (i.e. a process perspective) provides additional insights for G2G IS management in Flanders. The analysis takes a broader look on IS failure than the classic factor perspective by incorporating the dynamic IS context and its stakeholders.

A previous study of recurrent technological and political problems of Flemish G2G IS, showed that apparently controllable problems have deeper roots which discourage local stakeholders to support ISs (i.e. the focus on Flemish interests by idea champions, political disinterest in technology and a lack of coordination). In this study it appears that economic and juridical problems have the same roots. Yet these are also rooted in major differences in organisational capacities and juridical complications.

Insight in the deeper roots of recurrent IS problems adds, compared to factor research, a new piece to the complex IS failure puzzle. Given this knowledge, which action could managers take? Managers should consider that the 'network process' management' approach might be more suitable than an 'hierarchical project' management approach concerning Flemish G2G IS projects, they should have an eye for needs/capacity/speeds and could make politicians more aware of juridical consequences of their deeds, and in particular for the interplay of juridical aspects with ISs.

Our research findings are limited to Flemish G2G IS projects. Future research could study the roots of recurrent problems of G2G ISs in other regions or countries.

\section{References}

1. Bekkers, V.: The three faces of e-government: innovation, interaction and governance, in: AV. Anttiroiko et al. (eds)., Innovations in Public Governance. Series Innovation in the public sector. Amsterdam: IOS Press, 2011, pp. 194-216 (2011).

2. Bekkers, V., van Duivenboden, H. \& Thaens, M.: ICT and Public Innovation. Assessing the ICT-Driven Modernization of Public Administration, IOS Press, Amsterdam (2006)

3. Belanger, F. \& Tech, V.: Theorizing in Information Systems Research: using focus groups, Australasian Journal of Information Systems, 17(2), 109-135 (2012) 
4. Bigdeli, Z., Kamel, M. \& deCesare, S.: Inter-Organisational Electronic Info. Sharing in Local G2G Settings: A Socio-Technical Issue. European Conference on ISs, paper 79 (2011)

5. Dawes, S.: E-gov. \& innovation: a fresh look at experience, IFIP EGOV (2014)

6. Dawes, S., Cresswel, A.M., Pardo, T.A.: From 'Need to Know" to "Need to Share': Tangled Problems, Information Boundaries, and the Building of Public Sector Knowledge Networks. Public Administration Review, 69(3), 392-402 (2009)

7. De Bruyn, H., ten Heuvelhof, E. \& in 't Veld, R.: Process Management, Why Project Management Fails in Complex Decision Making, Springer, Heidelberg (2010)

8. Dwivedi, Y.K., Wastell, D., Laumer, S., Zinner, H. et al: Research on IS failures \& success: status update \& future directions. Info. System Frontiers, Springer. (2014)

9. Ebrahim, Z. \& Irani, Z.: E-government adoption: architecture and barriers, Business Process Management Journal, 11(5), 589-611(2005)

10. Edmiston, K.L.: State and local e-government. Prospects and Challenges. American Review of Public Administration, 33(1), 20-45 (2003)

11. Fountain, J.E.: Challenges to Organizational Change: Multi-Level Integrated Information Structures (MIIS), National Center for Digital Government. Paper 15 (2006)

12. Janssen, M., van der Voort, H., \& van Veenstra, A.F.: Failure of large transformation projects from the viewpoint of complex adaptive systems: Management principles for dealing with project dynamics, Information System Frontiers (2014)

13. Jing, F. \& Pengzhu, ZA: Field Study of G2G Information Sharing in Chinese Context Based on the Layered Behavioral Model, HICCS 42, 1-13 (2009)

14. Krueger, R.: Focus groups: a practical guide for applied research, Sage publications (1994)

15. Lam, W.: Barriers to e-government integration, Journal of Enterprise Information Management, 18(5), 511 - 530 (2005)

16. Moon, M.J.: The evolution of e-government among Municipalities; Rhetoric or Reality? Public Administration Review, 62(4), 424-433 (2002)

17. OECD: Innovating the Public Sector: from Ideas to Impact, Paris, 1-22 (2014)

18. Pardo, T. A., Nam, T., Burke, G.B.: E-Gov. Interoperability: Interaction of Policy, Management \& Technology. Social Science Computer Review, 1-17 (2011)

19. Pardo, T.A., \& Scholl, H.J.: Walking Atop the Cliffs: Avoiding Failure and reducing Risk in Large Scale E-government Projects. HICCS 35 (2002)

20. Peters, R.M., Janssen, M \& van Engers T.M.: Measuring e-Gov impact existing practices \& shortcomings, 6th International Conference of ECommerce, 480-489 (2004)

21. Petter, S., DeLone, W., \& McLean E.R.: Information Systems Success: The Quest for the Independent Variable Journal of MIS, 29(4), 7-61 (2013)

22. Sauer, C. : Why IS Fail: A Case Study Approach, Alfred Waller Publishers (1993)

23. Van Cauter, L., Snoeck M., Crompvoets J.: Removing the blinkers: what a process view learns about G2G information systems in Flanders. IFIP WG 8.5., Thessaloniki, (2015)

24. Yang, T.M., Pardo, T. \& Wu, Y.J.: How is info. shared across the boundaries of government agencies? An e-Gov. case study. Government Information Quarterly 31, 637-652 (2014)

25. Yang, T.M., Zheng, L., Pardo, T.: The boundaries of info. sharing \& integration: case study of Taiwan e-Gov.. Government Information Quarterly, 29,S51-S60 (2012) 